\title{
Thermodynamics of thallium alkanoates II. Heat capacity and thermodynamic functions of thallium(I) n-heptanoate ${ }^{a}$
}

\author{
S. P. NGEYI, F. L. LOPEZ DE LA FUENTE, ${ }^{b}$ J. A. R. CHEDA, \\ F. FERNANDEZ-MARTIN, ${ }^{c}$ and EDGAR F. WESTRUM, JR. \\ Department of Chemistry, University of Michigan, \\ Ann Arbor, Michigan 48109, U.S.A.
}

(Received 5 September 1984)

\begin{abstract}
The sub-ambient heat capacity of thallium(I) $n$-heptanoate is characterized by two sets of transitions between 262 and $301 \mathrm{~K}$. The lowest transition (at $262.8 \mathrm{~K}$ ) has a maximum $C_{p, \mathrm{~m}} / R \approx 700$. Next, a bifurcated pair (at 267.8 and $271.7 \mathrm{~K}$ ) has $\left(C_{p, \mathrm{~m}} / R\right.$ )'s $\approx 200$, and the highest bifurcated pair (at 297.2 and $300.9 \mathrm{~K}$ ) has maximum $\left(C_{p, \mathrm{~m}} / R\right)$ 's $\approx 450$ and $\approx 16000$. The corresponding values of $\Delta_{\mathrm{trs}} S_{\mathrm{m}}^{\circ} / R$ for the two sets are about $1.93_{5}$ and $2.21_{5}$. The heat capacities are in fair accord with the d.s.c. values of Fernandez-Martin, Lopez de la Fuente, and Cheda over the common range of superambient values. At $298.15 \mathrm{~K}$ the values of $\left\{S_{\mathrm{m}}^{\circ}(T)-S_{\mathrm{m}}^{\circ}(0)\right\} / R, \quad\left\{H_{\mathrm{m}}^{\circ}(T)-H_{\mathrm{m}}^{\circ}(0)\right\} / R$, and $-\left\{G_{\mathrm{m}}^{\circ}(T)-H_{\mathrm{m}}^{\circ}(0)\right\} / R T$ are $38.58,5514.7 \mathrm{~K}$, and 20.30. Smoothed thermodynamic values are tabulated at selected temperatures through melting.
\end{abstract}

\section{Introduction}

A recent paper describes heat-capacity measurements over the cryogenic region on thallium(I) $n$-hexanoate. The second thallium compound to be investigated is thallium(I) $n$-heptanoate (T17C). Studics by d.s.c. at higher temperatures have been published by Fernandez-Martin et al., ${ }^{(2)}$ and the thermophysical properties as measured previously have been summarized by Franzosini and Sanesi. ${ }^{(3)}$ Relatively little else is known about the compound, but thermal methods ${ }^{(4.5)}$ and microscopic methods ${ }^{(5-7)}$ have also been used in the superambient region. The phase behavior observed in the superambient region can be summarized as:

$$
\begin{aligned}
& \text { Crystal II = Crystal I = Mesomorphic liquid = Isotropic liquid } \\
& T_{\text {trs }}: \quad 301.9 \mathrm{~K} \quad 420.7 \mathrm{~K} \\
&
\end{aligned}
$$

The subambient phase behavior has not been investigated previously and will be seen to be complex on the basis of our thermophysical studies. Only the highest of the five transitions has been reported previously.

\footnotetext{
a This research was supported in part by the Structural Chemistry and Chemical Thermodynamics Program of the Chemistry Section of the National Science Foundation under grant CHE-7710049. The first paper in this series is reference 1.

${ }^{b}$ Address Departamento de Química Fisica, Facultad de Ciencias Químicas, Universidad Complutense, Madrid, Spain.

' Address: Instituto del Frio, CSIC, 28040 Madrid, Spain.
} 


\section{Experimental}

The sample of TI7C used is a portion from a batch prepared at the Universidad Complutense, Madrid, Spain and used for superambient d.s.c. studies. ${ }^{(2)}$ The salt was obtained by reaction of purified $n$-heptanoic acid with thallium carbonate in methanol according to the procedure of Meisel $e t$ al..$^{(4)}$ The salt was recrystallized several times from (ethanol +ether): infrared spectroscopic determinations failed to reveal any traces of water or free acid. In addition, the sample was analyzed by Spang Microanalytical Laboratory for all four elements and the reported values are H, 4.03 mass per cent, theoretical: 3.93 mass per cent; $\mathrm{C}, 25.37$ mass per cent, theoretical: 25.21 mass per cent; O, 9.75 mass per cent, theoretical: 9.59 mass per cent; and Tl, 60.94 mass per cent, theoretical: 61.27 mass per cent. Moreover, a d.s.c. purity determination using fractional-fusion techniques indicated a value of 99.89 moles per cent of liquid-soluble solid-insoluble purity.

The calorimetric measurements were made in the Mark X cryostat described previously. ${ }^{(8)}$ This calorimeter uses intermittent-heating adiabatic equilibrium methods. The programming, data logging, and calorimetry were done by automated computerization described elsewhere. ${ }^{(9)}$ All measurements of mass, time, resistance, etc., were referred to calibrations of the National Bureau of Standards. The sample loaded into the gold-plated OFHC copper calorimeter W-62 had a mass of $65.615 \mathrm{~g}$, which corresponds to an amount-of-substance factor of 5.083, on the basis of the 1978 IUPAC relative atomic masses. The buoyancy corrections are calculated on the assumed density of $2.85 \mathrm{~g} \cdot \mathrm{cm}^{-3}$. No crystallographic information is available for this compound nor for adjacent members of the homologous series. The closest member of the series for which the density is available is that of thallium acetate which has a density of $3.6 \mathrm{~g} \cdot \mathrm{cm}^{-3}$. Following evacuation, $2.4 \mathrm{kPa}$ of purified helium was added to the calorimeter to enhance thermal equilibration; the calorimeter was then sealed via a screw cap which pressed a gold gasket against the circular knife edge on the stainless-steel neck of the calorimeter. The calorimeter was sealed by a remotely operating hexagonal wrench within the vacuum chamber.

The thermal history of the thallium heptanoate sample is shown by the linear array: (solid arrows indicate cooling and dashed arrows indicate data acquisition ranges for various series).

$$
\begin{aligned}
& 343 \mathrm{~K} \stackrel{1 \mathrm{~h}}{\longrightarrow} 300 \mathrm{~K}(4 \mathrm{~d}) \stackrel{15 \mathrm{~h}}{\longrightarrow} 196 \mathrm{~K} \underset{\text { series I }}{\stackrel{14 \mathrm{~h}}{\longrightarrow}} 342 \mathrm{~K} \stackrel{9 \mathrm{~h}}{\longrightarrow} \\
& 196 \mathrm{~K} \underset{\text { series II }}{\stackrel{12 \mathrm{~h}}{\rightarrow}} 347 \mathrm{~K} \stackrel{12 \mathrm{~h}}{\longrightarrow} 208 \mathrm{~K}(3 \mathrm{~h}) \underset{\text { series III }}{\stackrel{7.5 \mathrm{~h}}{\longrightarrow}} 347 \mathrm{~K} \stackrel{15 \mathrm{~h}}{\longrightarrow} \\
& 253 \mathrm{~K}(2 \mathrm{~h}) \underset{\text { series IV }}{\approx 11 \mathrm{~h}} 348 \mathrm{~K} \stackrel{10 \mathrm{~h}}{\longrightarrow} 170 \mathrm{~K}(3 \mathrm{~h}) \underset{\text { series } \mathrm{v}}{\stackrel{10.5 \mathrm{~h}}{\rightarrow}} 306 \mathrm{~K} \stackrel{10 \mathrm{~h}}{\longrightarrow} \\
& 71 \mathrm{~K}(2 \mathrm{~h}) \underset{\text { series } \mathrm{VI}}{\stackrel{10 \mathrm{~h}}{\rightarrow}} 156 \mathrm{~K} \stackrel{10 \mathrm{~h}}{\longrightarrow} 90 \mathrm{~K} \underset{\text { series VII }}{\stackrel{13 \mathrm{~h}}{\longrightarrow}} 255 \mathrm{~K} \stackrel{1 \mathrm{~d}}{\longrightarrow} \\
& 60 \mathrm{~K}(6 \mathrm{~d}) \stackrel{12 \mathrm{~h}}{\longrightarrow} 6.5 \mathrm{~K} \stackrel{10 \mathrm{~h}}{\rightarrow} 106 \mathrm{~K}
\end{aligned}
$$


TABLE 1. Experimental values of heat capacity of thallium(I) $n$-heptanoate $\left(R=8.3144 \mathrm{~J} \cdot \mathrm{K}^{-1} \cdot \mathrm{mol}^{-1}\right)$

\begin{tabular}{|c|c|c|c|c|c|c|c|c|c|}
\hline$T / \mathbf{K}$ & $C_{p, \mathbf{m}} / R$ & $T / \mathrm{K}$ & $C_{p, \mathrm{~m}} / R$ & $T / \mathrm{K}$ & $C_{p, \mathrm{~m}} / R$ & $T / \mathbf{K}$ & $C_{p, \mathrm{~m}} / R$ & $T / \mathbf{K}$ & $C_{p, \mathrm{~m}} / R$ \\
\hline \multicolumn{2}{|c|}{ Series I } & 330.72 & 39.53 & 262.68 & 344 & \multicolumn{2}{|c|}{ Serics VI } & \multicolumn{2}{|c|}{ Series VIII } \\
\hline 264.83 & 74.40 & 338.13 & 39.17 & 262.79 & 546 & 78.36 & 12.766 & 6.63 & 0.33 \\
\hline 271.40 & 68.87 & 344.41 & 38.92 & 263.13 & 112.5 & 92.75 & 14.262 & 7.30 & 0.34 \\
\hline 280.67 & 34.74 & & & 264.13 & 37.620 & 96.55 & 14.574 & 8.14 & 0.45 \\
\hline 290.93 & 50.24 & \multirow{2}{*}{\multicolumn{2}{|c|}{$\begin{array}{c}\text { Series IV } \\
\Delta H_{+\mathrm{t}} \text { Det'n B }\end{array}$}} & 265.62 & 35.506 & 100.24 & 14.927 & 9.05 & 0.59 \\
\hline 298.04 & 87.10 & & & 266.97 & 48.26 & 104.04 & 15.262 & 9.91 & 0.719 \\
\hline 300.82 & 1528 & 285.18 & 36.075 & 267.83 & 126.0 & 107.92 & 15.541 & 10.78 & 0.859 \\
\hline 307.41 & 40.20 & 288.19 & 37.690 & 269.69 & 55.57 & 111.78 & 15.784 & 11.65 & 1.011 \\
\hline 312.79 & 39.71 & 289.75 & 39.380 & 271.54 & 128.4 & 115.60 & 16.225 & 12.62 & 1.194 \\
\hline 318.18 & 39.79 & 291.72 & 43.682 & 272.12 & 96.8 & 119.29 & 16.679 & 13.68 & 1.391 \\
\hline 323.57 & 39.91 & 293.52 & 56.330 & 272.74 & 105.8 & 122.90 & 16.723 & 14.75 & 1.613 \\
\hline 328.98 & 39.63 & 294.93 & 109.6 & 273.76 & 38.162 & 126.80 & 17.025 & 15.84 & 1.832 \\
\hline 334.41 & 39.37 & 296.31 & 144.3 & 275.28 & 34.237 & 130.95 & 17.317 & 16.94 & 2.057 \\
\hline \multirow[t]{2}{*}{339.85} & 39.07 & 299.02 & 72.14 & 276.87 & 33.932 & 135.02 & 17.605 & 18.07 & 2.175 \\
\hline & & 300.927 & 193.7 & 278.07 & 33.985 & 139.02 & 17.898 & 19.19 & 2.534 \\
\hline \multicolumn{2}{|c|}{ Series II } & 302.25 & 69.5 & 278.86 & 34.088 & 142.97 & 18.186 & 20.296 & 2.766 \\
\hline 197.41 & 22.124 & 305.65 & 40.39 & 279.65 & 34.315 & 146.84 & 18.436 & 21.36 & 2.998 \\
\hline 201.88 & 22.552 & 309.67 & 39.89 & 280.43 & 34.443 & 150.65 & 18.707 & 22.38 & 3,2197 \\
\hline 208.05 & 23.123 & 312.13 & 39.89 & 281.22 & 34.584 & 154.41 & 18.972 & 23.46 & 3.452 \\
\hline 214.19 & 23.676 & 313.17 & 39.86 & 282.00 & 34.785 & \multirow{2}{*}{\multicolumn{2}{|c|}{ Series VII }} & 24.59 & 3.700 \\
\hline 220.31 & 24.352 & 314.73 & 39.72 & 283.16 & 35.236 & & & 25.78 & 3.952 \\
\hline 226.42 & 25.063 & 316.81 & 39.78 & 284.69 & 35.720 & 94.96 & 14.451 & 27.02 & 4.221 \\
\hline 232.52 & 25.902 & 318.89 & 39.81 & 286.21 & 36.401 & 103.40 & 15.164 & 28.49 & 4.538 \\
\hline 238.61 & 26.773 & 322.90 & 39.90 & 287.70 & 37.221 & 111.42 & 15.878 & 30.096 & 4.884 \\
\hline 244.68 & 27.900 & 326.94 & 39.74 & 289.16 & 38.446 & 119.05 & 16.625 & 31.58 & 5.199 \\
\hline 250.79 & 28.976 & 333.22 & 39.36 & 290.58 & 40.482 & 126.37 & 17.002 & 32.96 & 5.497 \\
\hline 257.15 & 30.489 & 339.49 & 39.05 & 292.94 & 52.31 & 133.49 & 17.524 & 34.73 & 5.874 \\
\hline 261.63 & 108.9 & 345.76 & 38.82 & 294.93 & 109.6 & 140.42 & 18.011 & 36.93 & 6.329 \\
\hline 266.71 & 57.9 & \multirow{2}{*}{\multicolumn{2}{|c|}{ Series V }} & 295.44 & 159.6 & 147.19 & 18.489 & 39.13 & 6.757 \\
\hline 275.05 & 50.34 & & & 295.75 & 267.7 & 153.80 & 18.951 & 41.35 & 7.186 \\
\hline 285.12 & 36.35 & 195.72 & 21.996 & 295.98 & 344 & 160.28 & 19.394 & 43.81 & 7.648 \\
\hline 293.07 & 60.4 & 206.38 & 22.949 & 296.39 & 92.1 & 166.64 & 19.839 & 46.51 & 8.144 \\
\hline 298.03 & 88.2 & 216.67 & 23.973 & 297.17 & 42.849 & 172.88 & 20.285 & 49.22 & 8.620 \\
\hline 303.82 & 76.2 & 226.60 & 25.113 & 298.05 & 44.139 & 179.01 & 20.714 & 51.97 & 9.095 \\
\hline 312.12 & 39.81 & 236.21 & 26.357 & 298.90 & 45.88 & 185.01 & 21.173 & 55.11 & 9.605 \\
\hline 322.57 & 39.77 & 243.68 & 27.579 & 299.73 & 48.40 & 190.88 & 21.615 & 58.61 & 10.134 \\
\hline 331.43 & 39.54 & 249.15 & 28.555 & 300.47 & 58.13 & 195.51 & 22.003 & 62.11 & 10.678 \\
\hline 338.21 & 39.13 & 252.73 & 29.145 & 300.88 & 450 & 198.95 & 22.304 & 65.62 & 11.171 \\
\hline \multirow[t]{2}{*}{344.48} & 38.90 & 254.48 & 29.564 & 300.92 & 2368 & 202.36 & 22.590 & 69.16 & 11.611 \\
\hline & & 256.21 & 30.079 & 300.93 & 1727 & 205.72 & 22.903 & 72.72 & 12.053 \\
\hline \multicolumn{2}{|c|}{ Series III } & 257.92 & 30.443 & 300.95 & 1289 & 210.63 & 23.423 & 76.42 & 12.508 \\
\hline 221.59 & 24.481 & 259.19 & 30.867 & 301.27 & 82.2 & 218.44 & 24.132 & 84.33 & 13.452 \\
\hline \multicolumn{2}{|c|}{$\Delta H_{\mathrm{trs}}$ Det'n A } & 260.02 & 31.375 & 302.12 & 42.7 & 227.06 & 25.203 & 92.37 & 14.227 \\
\hline 263.80 & 42.99 & 260.84 & 32.406 & 303.22 & 41.8 & 235.12 & 26.251 & 96.52 & 14.636 \\
\hline 267.01 & 59.74 & 261.59 & 38.761 & 304.34 & 40.82 & 243.20 & 27.522 & 100.60 & 14.974 \\
\hline 272.45 & 59.95 & 262.14 & 80.5 & 305.47 & 40.43 & 251.24 & 29.564 & 104.65 & 15.277 \\
\hline 281.39 & 34.95 & 262.44 & 168.9 & & & & & & \\
\hline 306.85 & 54.45 & 262.59 & 283.6 & & & & & & \\
\hline
\end{tabular}


The obligatory rejection of the lower transition set for series IV is seen to have been occasioned by our only having cooled to $253 \mathrm{~K}$ - even though it was done very slowly.

The values of $C_{p}$ measured have a standard deviation varying from 2 per cent at $6 \mathrm{~K}$ to 0.5 per cent at $10 \mathrm{~K}$ and 0.08 per cent above this temperature to $350 \mathrm{~K}$. The d.s.c. data ${ }^{(2)}$ are less accurate. The values of the smoothed integrated thermophysical properties are more reliable and have a standard deviation of 0.06 per cent above $100 \mathrm{~K}$.

The heat capacity of the sample decreased from 95 per cent of the total (sample + calorimeter + helium) at $6 \mathrm{~K}$ to 66 per cent at $131 \mathrm{~K}$ and then increased gradually to 76 per cent at $350 \mathrm{~K}$, except, of course, in transition regions.

\section{Results and discussion}

Experimental heat capacities given in tables 1 and 2 are plotted in figure 1 . These results are given in chronological order. Within a series the temperature interval of

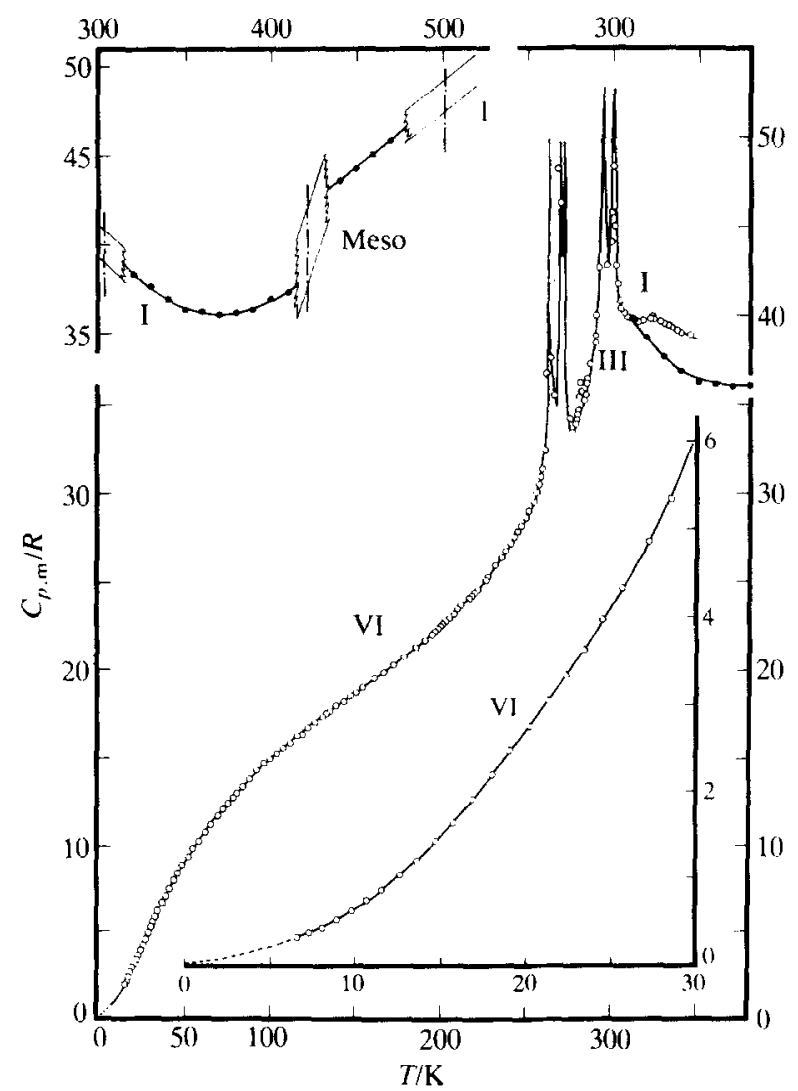

FIGURE 1. Heat capacity of thallium(I) n-heptanoate with phase designations. $O$. This work; Q, reference 2 by d.s.c. 
each measurement may usually be ascertained from the difference between adjacent mean temperatures. These results have been fitted to a series of orthogonal polynomials in the region of normal heat capacity. Integration of these polynomials yields the thermodynamic functions. Tabulation of the smooth $C_{p, \mathrm{~m}} / R$ values are given for selected temperatures in table 3 . The heat-capacity values within transition regions given in this table are those both for the measured-compound heat capacity and for the estimated lattice contributions obtained by the procedure followed in previous papers of a related series. ${ }^{(10-13)}$

It is interesting that both sets of results show the heat capacity to diminish for some tens of kelvins above the II-to-I transition. There is a significant discrepancy in the pattern of this decrease. Our results are highly reproducible over four separate and independent determinations made in this region. Above $310 \mathrm{~K}$ our $C_{p . \mathrm{m}} / R$ values show a deviation from the d.s.c. values of reference 2 in the form of a broad

TABLE 2. Summary of transition sets for thallium(I) n-heptanoate $\left(R=8.3144 \mathrm{~J} \cdot \mathrm{K}^{-1} \cdot \mathrm{mol}^{-1}\right)$

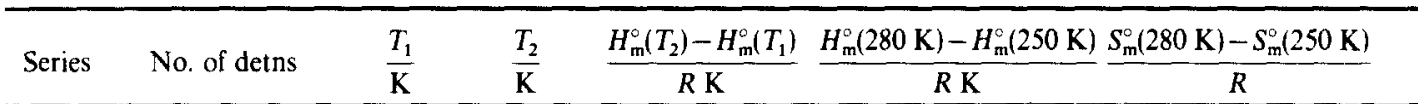

Transition set VI-to-V, V-to-IV, and IV-to-III

$\begin{array}{rcrrr}\text { I } & 3 & 261.65 & 286.54 & 1355.9 \\ \text { II } & 4 & 253.82 & 279.45 & 1355.6 \\ \text { III } & 4+\text { Detn A } & 229.34 & 287.23 & 2302.9 \\ \text { IV } & \Delta_{\text {trs }} H_{\mathrm{m}}^{\circ} \text { Detn B } & 253.72 & 282.72 & 1344.8 \\ \text { V } & 27 & 255.35 & 280.82 & 1355.5\end{array}$

Graphical integration

Mean:

Lattice contribution:

$\Delta_{\text {trs }} H_{\mathrm{m}}^{\circ}(\mathrm{VI}$-to-V-to-IV-to-III)/R K:

$\Delta_{\mathrm{trs}} S_{\mathrm{m}}^{\mathrm{i}}$ (VI-to-V-to-IV-to-III) $/ R$ :

$$
\begin{aligned}
& \Delta_{\mathrm{V} 1}^{\mathrm{V}} H_{\mathrm{m}}^{\circ} / R \mathrm{~K}=236.5 \\
& \Delta_{\mathrm{V}}^{\mathrm{V}} H_{\mathrm{m}}^{\circ} / R \mathrm{~K}=140.3 \\
& \Delta_{\mathrm{VV}}^{\mathrm{VI}} H_{\mathrm{m}}^{\mathrm{o}} / R \mathrm{~K}=141.5
\end{aligned}
$$

Transition set III-to-II, II-to-I

$\begin{array}{rrrr}\text { I } & 4 & 274.80 & 300.86 \\ \text { II } & 5 & 279.45 & 306.89 \\ \text { III } & 2 & 275.56 & 326.47 \\ \text { IV } & 12 & 282.72 & 311.61 \\ \text { V } & 29 & 280.04 & 306.04\end{array}$

Graphical integration:

Mean:

Lattice contribution:

$\Delta_{\mathrm{trs}} H_{\mathrm{m}}^{\circ}$ (III-to-II, II-to-I)/R K:

$\Delta_{\text {trs }} S_{\mathrm{m}}^{\mathrm{c}}$ (III-to-II. II-to-I) $/ R$ :

$$
\begin{aligned}
\Delta_{\mathrm{III}}^{\mathrm{II}} H_{\mathrm{m}}^{\circ} / R \mathrm{~K} & =355.5 \\
\Delta_{\mathrm{lI}}^{\mathrm{I}} H_{\mathrm{m}}^{\circ} / R \mathrm{~K} & =306.2
\end{aligned}
$$

$1490.2 \quad 1748.0$

$1654.5 \quad 1759.8$

$2557.2 \quad 1749.8$

$1714.0 \quad 1751.1$

1585.9

1745.8
1750

$\overline{1750.9} \quad \overline{5.89_{6}}$

$\frac{1089.2}{661.7}$

$3.69_{1}$

$2.20_{5}$

$\Delta_{\mathrm{III}}^{\mathrm{II}} S_{\mathrm{m}}^{\circ} / R=1.20_{\mathrm{S}}$

$\Delta_{\mathrm{II}} S_{\mathrm{m}}^{\circ} / R=1.01_{0}$

\footnotetext{
${ }^{a}$ The Series IV value and the graphical integration were not included in the mean.
} 
diffuse transition with a $\Delta_{\mathrm{trs}} H_{\mathrm{m}}^{\circ} / R$ of about $56 \mathrm{~K}$. It is also interesting to note that their $\Delta_{\mathrm{ll}}^{\mathrm{l}} H_{\mathrm{m}}^{\circ} / R$ is about $15 \mathrm{~K}$ higher than the area under our peak. Since the samples are from the same batch, it is difficult to account for the discrepancy. However, the decrease has been noted ${ }^{(2)}$ as an odd-even effect in T13C, T15C, and more prominently in T17C. Moreover, it has been suggested ${ }^{(2)}$ that in pure samples the heat capacity would be monotonic increasing.

In evaluating the superambient thermodynamic functions, we chose to use their heat-capacity curve which joins ours smoothly at $310 \mathrm{~K}$ and fits with the mesomorphic and isotropic liquid transitions. We have chosen to use the d.s.c. data in this region in preference to our own in evaluating thermodynamic functions at superambient temperatures with the reservation that since adiabatic equilibrium calorimetry may be more reliable than d.s.c., we shall need to revise this judgment when our measurements have been extended to higher temperatures.

Although it might be surmised that one or more of the transitions might be occasioned by impurities, this possibility is ruled out by the following arguments. The most likely impurities are heptanoic acid and water. The melting temperature of the former has been recorded as $265.83 \mathrm{~K},{ }^{(13)}$ and that for ice is $273.15 \mathrm{~K}$. Hence, either the transition at $267.8 \mathrm{~K}$ or that at $271.7 \mathrm{~K}$ might be suspect. The values for the microanalysis of the sample are within experimental reliability. However, if we utilize the reported carbon analysis and assume the sample is made up of a mixture of thallium heptanoate and heptanoic acid, we would calculate the presence of mole fraction 0.011 of the acid. The calculated values for hydrogen, oxygen, and thallium on the assumption of this mole fraction of impurity $(4.05,9.75$, and 60.24 mass per cent) are consistent with the reported values. However, it would require a mole fraction of acid of about 0.08 to account for either of the above transitions--about eight times the amount indicated by (this interpretation of) the gravimetric analysis.

Moreover, an 8 moles per cent heptanoic acid contamination should be readily detectable by the infrared technique used, and fractional-fusion analysis indicates a maximum mole fraction of 0.001 of solid-insoluble liquid-soluble impurity. If it is assumed that the heptanoic acid (and ice) are immiscible in the solid sample, we can rule out the possibility that this peak results from heptanoic acid contamination. Were we to consider the possibility of water contamination, using the carbon content as a criterion, we would note that water could only contribute to a decrease in the apparent fraction of carbon-not to the increase observed. Disregarding the carbon and using observed oxygen mole fraction instead as a criterion, a mole fraction 0.031 of water might be expected. This is consistent with hydrogen and thallium mole fractions. However, the mole fraction of melting ice required to produce the thermal effect associated with the $271.7 \mathrm{~K}$ transition would be about 0.20 . This is totally inconsistent with the gravimetric and infrared results and-if solubility of water in the solid sample is negligible - with the fractional-fusion determination by a factor of 20 . In view of the careful drying of the sample at elevated temperatures, it is inconceivable that sufficient water could be present to produce such a peak. Solubilities of the salt are not available so that we might argue whether or not the melting-temperature depression needed to account for such a difference in the melting-temperature observed is possible. Moreover, it should be 
TABLE 3. Thermodynamic properties of thallium(I) $n$-heptannate $\left(R=8.3144 \mathrm{~J} \cdot \mathrm{K}^{-1} \cdot \mathrm{mol}^{-1}\right)$

\begin{tabular}{|c|c|c|c|c|}
\hline$\frac{T}{\mathrm{~K}}$ & $\frac{C_{p, \mathrm{~m}}}{R}$ & $\frac{S_{\mathrm{m}}^{\circ}}{R}$ & $\frac{H_{\mathrm{m}}^{\circ}(T)-H_{\mathrm{m}}^{\circ}(0)}{R \mathrm{~K}}$ & $\frac{-\left\{G_{\mathrm{m}}^{\mathrm{o}}(T)-H_{\mathrm{m}}^{\mathrm{o}}(0)\right\}}{R T}$ \\
\hline 0 & 0 & 0 & 0 & 0 \\
\hline 5 & 0.179 & 0.059 & 0.222 & 0.0146 \\
\hline 10 & 0.738 & 0.334 & 2.36 & 0.0980 \\
\hline 15 & 1.656 & 0.798 & 8.24 & 0.2491 \\
\hline 20 & 2.710 & 1.418 & 19.14 & 0.4613 \\
\hline 30 & 4.865 & 2.923 & 56.97 & 1.0238 \\
\hline 40 & 6.928 & 4.611 & 116.14 & 1.707 \\
\hline 50 & 8.758 & 6.357 & 194.7 & 2.462 \\
\hline 60 & 10.348 & 8.098 & 290.4 & 3.257 \\
\hline 70 & 11.740 & 9.800 & 401.1 & 4.070 \\
\hline 80 & 12.941 & 11.448 & 524.6 & 4.890 \\
\hline 90 & 13.982 & 13.034 & 659.3 & 5.708 \\
\hline 100 & 14.903 & 14.555 & 803.8 & 6.517 \\
\hline 120 & 16.51 & 17.42 & 1118.4 & 8.098 \\
\hline 140 & 17.97 & 20.08 & 1463.5 & 9.622 \\
\hline 160 & 19.37 & 22.57 & 1836.9 & 11.086 \\
\hline 180 & 20.80 & 24.35 & 2238.4 & 12.494 \\
\hline 200 & 22.38 & 27.20 & 2669.8 & 13.85 \\
\hline 220 & 24.33 & 29.42 & 3136.0 & 15.166 \\
\hline 240 & 26.99 & 31.64 & 3647.6 & 16.44 \\
\hline \multirow[t]{2}{*}{$250^{a}$} & 28.72 & 32.78 & 3925.9 & 17.08 \\
\hline & {$[28.72]$} & [32.78] & [3925.9] & {$[17.08]$} \\
\hline \multirow[t]{2}{*}{260} & 31.36 & 33.95 & 4223.5 & 17.71 \\
\hline & {$[30.45]$} & [33.94] & [4221.6] & {$[17.70]$} \\
\hline \multirow[t]{2}{*}{$262.8^{b}$} & $(\approx 700)$ & $(34.27)$ & $(4307.6)$ & $(17.88)$ \\
\hline & [30.95] & {$[34.27]$} & [4307.6] & {$[17.88]$} \\
\hline \multirow{3}{*}{$262.8^{b}$} & & Phase V & & \\
\hline & $(\approx 700)$ & $(35.17)$ & $(4542.8)$ & $(17.88)$ \\
\hline & [33.95] & {$[34.27]$} & [4307.6] & {$[17.88]$} \\
\hline \multirow[t]{2}{*}{$265.6^{\circ}$} & $(\approx 35.5)$ & $(35.52)$ & $(4639.2)$ & $(18.06)$ \\
\hline & {$[33.95]$} & {$[34.63]$} & [4402.7] & [18.05] \\
\hline \multirow[t]{2}{*}{$267.8^{\circ}$} & $(\approx 200)$ & $(35.82)$ & $(4713.9)$ & $(18.21)$ \\
\hline & [33.95] & [34.92] & {$[4477.4]$} & [18.20] \\
\hline \multirow{3}{*}{$267.8^{b}$} & & Phase IV & & \\
\hline & $(\approx 200)$ & $(36.34)$ & $(4854.1)$ & $(18.21)$ \\
\hline & [33.95] & {$[34.92]$} & {$[4477.4]$} & {$[18.20]$} \\
\hline \multirow[t]{2}{*}{$270^{c}$} & $(\approx 43)$ & $(36.62)$ & $(4928.8)$ & $(18.36)$ \\
\hline & [33.95] & {$[35.20]$} & {$[4552.0]$} & {$[18.34]$} \\
\hline \multirow[t]{2}{*}{$271.7^{b}$} & $(\approx 200)$ & $(36.83)$ & $(4986.6)$ & $(18.48)$ \\
\hline & [33.95] & {$[35.41]$} & {$[4609.7]$} & {$[18.45]$} \\
\hline \multirow{3}{*}{$271.7^{b}$} & & Phase III & & \\
\hline & $(\approx 200)$ & $(37.35)$ & $(5127.8)$ & (18.48) \\
\hline & [33.95] & {$[35.41]$} & [4609.7] & [18.45] \\
\hline \multirow[t]{2}{*}{$276.9^{\circ}$} & $(33.95)$ & $(37.99)$ & $(5303.6)$ & $(18.84)$ \\
\hline & [33.95] & {$[36.05]$} & {$[4785.2]$} & {$[18.77]$} \\
\hline 280 & 34.35 & 38.37 & 5409.9 & 19.05 \\
\hline 290 & 39.4 & 39.64 & 5772.2 & 19.74 \\
\hline \multirow{2}{*}{$296.2^{b}$} & $(\approx 500)$ & $(40.28)$ & $(5959.8)$ & $(20.16)$ \\
\hline & [33.95] & [38.34] & [5441.5] & {$[19.97]$} \\
\hline
\end{tabular}


TABLE 3-continued

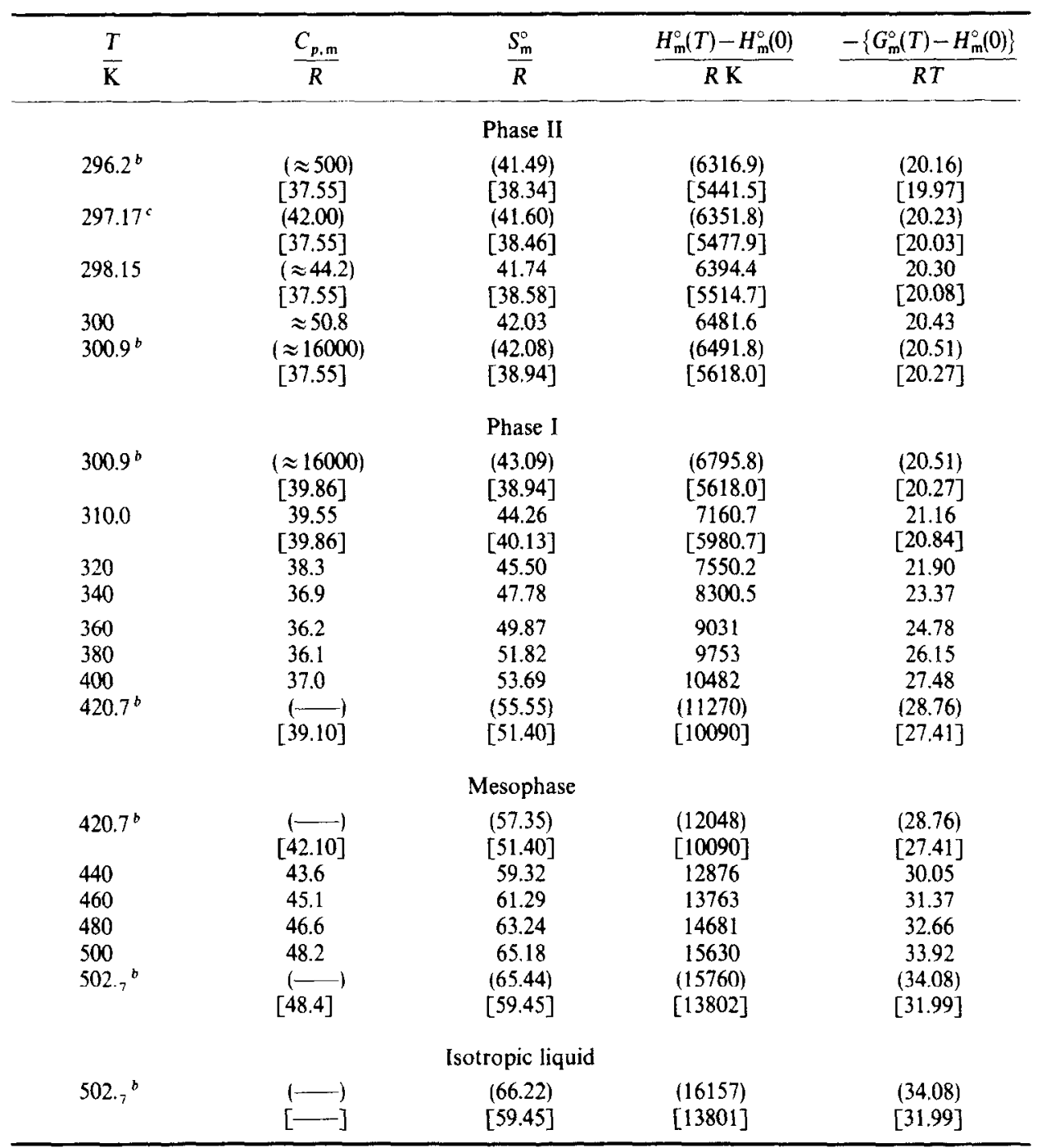

${ }^{a}$ Quantities in square brackets represent estimated lattice heat capacities at indicated temperature.

${ }^{b}$ Quantities in parentheses represent estimated heat capacities or other thermodynamic functions estimated on the assumption that the transitions are truly isothermal at the transition temperatures indicated.

' Quantities in parentheses are at minimum points between bifurcated transitions. Hence, values neither in parentheses nor brackets are real values at selected temperatures indicated. 


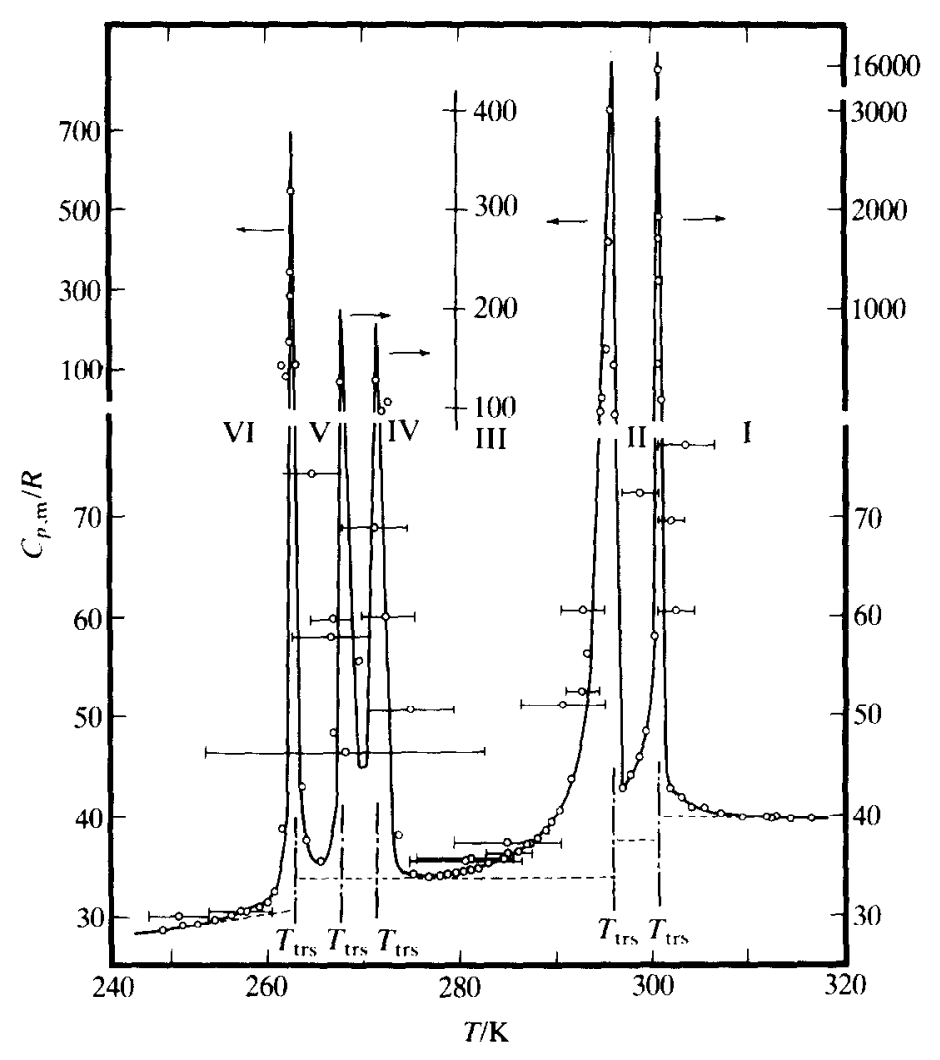

FIGURE 2. Sub-ambient transitions in thallium(I) $n$-heptanoate. Note adjuvant scales for peak values and phase designations. Horizontal bars indicate temperature increments of enthalpy-type determinations. Lattice heat-capacity contributions are indicated by dashed lines.

noted that water in the sample would be expected largely to hydrolyze the salt to acid and thallium hydroxide under the drying procedure used.

The smoothed values of the thermodynamic properties based on the information in the preceding two tables are summarized in table 3 . For convenience in giving values in the transition regions and in indicating the current basis of estimating lattice heat-capacity contributions, the entire transition contribution (measured minus lattice) is attributed to an isothermal absorption of enthalpy. Heat capacities in parentheses ( ) are estimated; the other thermodynamic values in parentheses are predicted on the above attribution and are clearly more or less at variance with experiment-as may be noted in figure 2 .

For completeness, table 3 includes also the superambient d.s.c. results of reference 2 (compare table 4), and our lattice contribution estimates are shown in square brackets [ ]. Phases in this table and the figures have been indicated in the usual fashion with Roman numbers increasing below the fusion to a mesomorphic phase. 
TABLE 4. Summary of transition properties of thallium(I) n-heptanoate ${ }^{a}$

\begin{tabular}{lcccc}
\hline \multicolumn{1}{c}{ Transition } & $T_{\mathrm{trs}}$ & $\Delta_{\mathrm{trs}} \mathrm{H}_{\mathrm{m}}^{\circ} / R \mathrm{~K}$ & $\Delta_{\mathrm{trs}} S_{\mathrm{m}}^{\mathrm{c}} / R$ & Reference \\
\hline VI-to-V & 262.8 & 236.5 & $0.89_{5}$ & This work \\
V-to-IV & 267.8 & 140.3 & $0.52_{4}$ & This work \\
IV-to-III & 271.7 & 141.5 & $0.52_{0}$ & This work \\
III-to-II & 296.2 & 355.5 & $1.20_{5}$ & This work \\
II-to-I & 300.9 & 306.2 & $1.01_{0}$ & This work \\
& 301.9 & 319 & 1.06 & 2 \\
I-to-Mesophase & 299 & 332 & 1.11 & 4 \\
& 420.7 & 758 & 1.80 & 2 \\
Mesophase-to-Isotropic liquid & 419 & 755 & 1.80 & 4 \\
& 502.0 & 397 & 0.79 & 2 \\
\hline
\end{tabular}

${ }^{a}$ Values from references 2 and 4 were determined by d.s.c.

The sum of the seven transitional entropies between $262 \mathrm{~K}$ and $502 \mathrm{~K}$ as $\Delta_{\mathrm{trs}} S_{\mathrm{m}}^{\circ} / R$ is 6.73 , most of which occurs below $300 \mathrm{~K}$ and is, therefore, of little interest for conventional energy-storage purposes. It is, however, suggestive of the nature of these materials. All the transitions are relatively sharp and easily reproducible, but the high heat capacities of the II-to-I transition are especially noteworthy. The lack of structural information precludes interpretation of the transitions.

\section{REFERENCES}

1. Boerio-Goates, J.; Lopez de la Fuente, F. L.; Cheda, J. A. R.; Westrum. E. F., Jr. J. Chem. Thermodynamics 1985, 17, 401.

2. Fernandez-Martin, F.; Lopez de la Fuente, F. L.; Cheda, J. A. R. Thermochimica Acta 1983, 73, 109.

3. Franzosini, P.; Sanesi, M. Thermodynamic and Transport Properties of Organic Salts. Pergamon: London. 1980.

4. Meisel, T.; Seybold, K.; Halmos, Z.; Roth, J.; Mélykuti, Cs. J. Therm. Anal. 1976, 10, 419.

5. Lindau, J.; Diele, S.; Krüger, H.; Dôrfler, H.-D. Z. Phys. Chem. 1981, 262, 775.

6. Baum, E.; Demus, D.; Sackmann, H. Wiss. Z. Univ. Halle 1970, XIX, 370.

7. Walter, R. Ber. Deut. Chem. 1926, 59, 963.

8. Westrum, E. F.. Jr. Proceedings NATO Advanced Study Institute on Thermochemistry at Viana do Castello, Portugal. Ribeiro da Silva, M. A. V.: editor. Reidel: New York. 1984, p. 745.

9. Westrum, E. F., Jr.; McCullough, J. P. Experimental Thermodynamics. Scott, D. W.; McCullough, J. P.: editors. Butterworths: New York. 1968, pp. 337-367.

10. Franzosini, P.; Westrum, E. F., Jr., Plautz, W. A. J. Chem. Thermodynamics 1983, 15, 609.

11. Franzosini, P.; Westrum, E. F., Jr. J. Chem. Thermodynamics 1984, 16, 81.

12. Franzosini, P.; Westrum, E. F., Jr. J. Chem. Thermodynamics 1984, 16, 127.

13. Franzosini, P.; Plautz, W. A.; Westrum, E. F., Jr. J. Chem. Thermodynamics 1983, 15, 445.

\section{Note added in proof}

Subsequent to the submission of this paper, further d.s.c. measurements at Madrid on the sample used for cryogenic measurements indicated that it had undergone change tentatively ascribed to formation of some amount of a (salt + acid) complex, producing the transition at $297 \mathrm{~K}$ and the deviation about $323 \mathrm{~K}$. Hence, thermodynamic properties at higher temperatures - other than the heat capacitymight need slight adjustment. 